\title{
Molecular variation within and among species of Harpellales
}

Alexandra M. Gottlieb

Robert W. Lichtwardt ${ }^{1}$

Department of Ecology and Evolutionary Biology, University of Kansas, Lawrence, Kansas 66045-2106

\begin{abstract}
Intra- and interspecific variation of the nuclear ribosomal internal transcribed spacers (ITS) of 77 Smittium isolates and related genera was studied using RFLP. Due to the sequence and length variation encountered, the ITS is unsuitable for comparison at the species level within Smittium, as presently delimited. Intra- and interspecific variation of $18 \mathrm{~S}$ rDNA was also analyzed. Cladistic analysis of 32 new $18 \mathrm{~S}$ rDNA sequences resolved at least five lineages and suggests that Smittium is not monophyletic. In addition, 17 18S rDNA sequences from 5 orders of Zygomycota were included to assess phylogenetic relationships with the Trichomycetes. The kickxellid origin of Trichomycetes was not strongly supported.
\end{abstract}

Key Words: 18S rDNA, ITS, phylogeny, RFLP, Smittium, Trichomycetes, Zygomycota

\section{INTRODUCTION}

The class Trichomycetes (Zygomycota) consists of a worldwide group of fungi that have various relationships with their arthropod hosts (Horn and Lichtwardt 1981, Lichtwardt 1986, 1996, Misra 1998). Known associations range from commensalistic to deleterious and possibly mutualistic in some cases (Lichtwardt 1986). The class consists of three orders, Harpellales, Asellariales and Eccrinales, of which only Harpellales contains culturable species. Traditionally, the order Amoebidiales has been placed in the same class. Although Amoebidiales and Harpellales share some similarities that perhaps reflect convergence attributable to having evolved under similar habitat constraints, they are not related phylogenetically (Lichtwardt 1986). There is evidence that zygomycetes belonging to the order Kickxellales and some Harpellales share common ancestry. They have some serological affinities (Sangar et al 1972, Peterson and Lichtwardt 1987) and similarities in septal and cell

Accepted for publication July 5, 2000.

Corresponding author, email: licht@eagle.cc.ukans.edu wall structure, and both orders produce basipetal monosporous sporangia (Moss and Young 1978). In particular, a bifurcate type of septum has been reported in Harpellales (Farr and Lichtwardt 1967), Asellariales (Manier 1973, Saikawa et al 1997, Moss 1975), Kickxellales (Young 1969), Dimargaritales (Saikawa 1977, Jeffries and Young 1979) and Mersitaciaceae (Entomophthorales) (Saikawa 1989). However, Porter and Smiley (1979) concluded that the Harpellales, Kickxellales and Mucorales were not closely related based on disparate RNA molecular weights. Walker's (1984) 5S rRNA sequence comparison indicated that Harpellales were more related to Mucorales than to Kickxellales, but the differences were too small to be convincing. Recently, O'Donnell et al (1998) showed certain phylogenetic relatedness in the sequences of the $18 \mathrm{~S}$ ribosomal DNA of some Kickxellales and four representatives of the Harpellales.

Emphasis in this study is on the trichomycete genus Smittium Poisson (Harpellales), with related fungal taxa included to give a broader perspective. The Harpellales currently includes 33 genera and 141 species (Misra and Lichtwardt 2000). At present only 7 genera are available in axenic culture. The genus Smittium has 55 described morphological species, all characterized by ellipsoidal to almost cylindrical trichospores (unispored sporangia) with a collar and a single appendage; zygospores, when present, are biconical to fusiform and obliquely attached to the zygosporophore and also have a collar and a single appendage (Lichtwardt 1986). The number of appendages is considered a generic character (Lichtwardt 1996). Trichospore appendages of Harpellales and sporangiospore appendages of one representative of Eccrinales [Astreptonema gammari (Léger \& Duboscq) Manier] are different in structure and ontogeny, presumably a result of convergent evolution in species subjected to similar environmental pressures (Moss 1979). Physiological studies of some Smittium cultures were conducted by Starr et al (1979), Williams (1983a, b) and Horn (1989a), among others. More recently, Grigg and Lichtwardt (1996) studied the isozyme variation of a worldwide sample of culturable trichomycetes.

Hosts of the Harpellales are larval stages of primitive orders of aquatic insects, namely Ephemerop- 
tera, Plecoptera and nematoceran Diptera. Patterns of Trichomycete infestation of chironomids (Chironominae, Podonominae, Orthocladiinae, Diamesinae) at the subfamily and generic levels were suggestive of a high degree of co-evolution among trichomycetes and their hosts (Slaymaker et al 1998). Some species of Smittium have a very wide distribution, while other species may be restricted geographically due to high host specificity or to poor dispersion. Worldwide distribution may be an expression of antiquity of the class, rather than the dispersal ability of individual species (Lichtwardt 1994a).

Analysis of nuclear ribosomal DNA (rDNA) regions has been applied to many fungal systematic questions (Bruns and Szaro 1992, Bruns et al 1992, Feibelman et al 1994, Dick et al 1999). Several studies have shown that the internal transcribed spacer (ITS) regions are often variable among fungal species (Gardes et al 1991, Hibbett and Vilgalys 1991, Feibelman et al 1994, Lobuglio et al 1993, Lloyd-MacGilp et al 1996). However, intraspecific heterogeneity also has been reported (Bunyard et al 1996). Nucleotide sequences of the small and large ribosomal subunit genes (18S and 28S) are more conserved, and thus have been generally used for comparison at higher taxonomic levels (Bruns and Szaro 1992, Bruns et al 1992, Berbee et al 1995, Gargas and Taylor 1995, Hibbett et al 1997, Harrington et al 1999). These molecules have divergent domains that form stem loops of relaxed secondary structure that are known to be variable in shape and in size among phylogenetically distant taxa (Bruns and Szaro 1992, Hillis and Dixon 1991). The existence of among-site rate variation within $18 \mathrm{~S}$ rDNA allows the same region to be used for both higher and lower relationships (Abouheif et al 1998). Highly conserved sites could be used for deep divergence but contribute little to phylogenetic information about recent divergences, while highly variable sites can recover recent divergences (Abouheif et al 1998).

The first objective of this study was to determine the suitability of the ITS region as a genetic marker by assessing inter- and intraspecific variation in several species of Smittium by means of PCR-RFLP and DNA sequencing. The second objective was to use cladistic analysis of $18 \mathrm{~S}$ rDNA sequences to elucidate phylogenetic relationships and to determine whether morphologically defined species are supported by the phylogenetic data. We tested the hypothesis that the genus Smittium is monophyletic and analyzed the phylogenetic relationships among 23 species.

\section{MATERIALS AND METHODS}

Cultures.-The organisms used in this study (TABLE I) were selected to obtain the maximal range in geographical and host diversity. When available, multiple isolates of several species of Smittium were examined. Mycelia were grown in liquid tryptone-glucose-salts medium TGv (Lichtwardt $1986)$ in a rotary shaker $(200 \mathrm{rpm})$ at $22 \mathrm{C}$. After $1-2 \mathrm{wk}$, mycelia were either lyophilized or harvested by vacuum filtration.

DNA extraction.-CTAB buffer-suspended samples (2\% CTAB, 1.4 M NaCl, 0.1 M Tris- $\mathrm{HCl}$ pH 8.0, 0.25 mM EDTA) were frozen and thawed at least twice by submerging the tubes into liquid nitrogen and incubating at $65-70 \mathrm{C}$ in a heat block. After the final thaw, mycelia were crushed with a sterile glass pestle and incubated for $30 \mathrm{~min}$ at $65 \mathrm{C}$. One volume of chloroform was added to each sample and mixed by vortexing for $10-15 \mathrm{~s}$. Samples were centrifuged at $12000 \mathrm{~g}$ for $10 \mathrm{~min}$ at room temperature. DNA was precipitated from the aqueous supernatant with two volumes of $100 \%$ ethanol $(-20 \mathrm{C})$ and pelleted with a 5 min centrifugation at $12000 \mathrm{~g}$. After a $70 \%$ ethanol (ice-cold) wash, the genomic DNA was redissolved in TE buffer $(10 \mathrm{mM}$ Tris-HCl pH 8.0, $1 \mathrm{mM}$ EDTA $\mathrm{pH} 8.0)$. The DNA extracts were treated with RNAse ONE (Promega Corp., Madison, Wisconsin) for $30 \mathrm{~min}$ at $37 \mathrm{C}$ and then extracted with chloroform, precipitated with ethanol, and resuspended in 50$100 \mu \mathrm{L}$ of TE buffer.

PCR amplification.-ITS amplification was carried out by using primers ITS4 and ITS5 (White et al 1990) and 5.8S and 5.8SR (Vilgalys and Hester 1990). Primer pairs ITS55.8S and ITS4-5.8SR were used to amplify ITS 1 and ITS 2 regions, respectively. Amplification of the $18 \mathrm{~S}$ rDNA was done either using universal primers NS1-NS8 (White et al 1990) or using universal and zygomycete-specific primers (O'Donnell et al 1998) NS1-Z411G and Z31G-NS8. Amplifications were performed in $0.225 \mathrm{mM}$ of each dNTP (Promega Corp., Madison, Wisconsin), $0.25 \mathrm{mM}$ of each primer, $10 \%$ of $10 \mathrm{X}$ buffer $(0.5 \mathrm{M} \mathrm{KCl}, 0.1 \mathrm{M}$ Tris- $\mathrm{HCl} \mathrm{pH} 8.4,25$ $\mathrm{mM} \mathrm{MgCl}_{2}, 1 \mathrm{mg} / \mathrm{mL}$ gelatin) and sterile double-distilled water. Taq DNA polymerase (Promega Corp., Madison, Wisconsin) was added at 2.5 units per $100 \mu \mathrm{L}$ of reaction mix. Total volume was adjusted to 20,50 or $100 \mu \mathrm{L}$ as needed. One $\mu \mathrm{L}$ of genomic DNA template was used in each $20 \mu \mathrm{L}$ reaction. Conditions for PCR amplification were those of Vilgalys and Hester (1990). Amplifications were carried out in a Perkin-Elmer Gene Amp PCR System 2400 Thermal Cycler. Control samples without DNA template were included in each PCR run. PCR products were checked by electrophoresing $1 \mu \mathrm{L}$ aliquots in $1 \%$ or $2 \%$ agarose gels (Fisher Sci., Pittsburgh, Pennsylvania) in $1 \mathrm{X}$ TAE buffer $(0.04 \mathrm{M}$ Tris, $1 \mathrm{mM}$ EDTA pH 8.0, 0.114\% glacial acetic). Gels were stained with ethidium bromide for 20-30 min and photographed under UV light. Each PCR amplification was repeated at least twice.

Restriction endonuclease digestions.-Single restriction endonuclease digests of amplified products were performed after chloroform extraction and ethanol precipitation, or directly on an aliquot of the PCR reaction. Digestions were done using $0.5-0.7$ units of each endonuclease per $\mu \mathrm{g}$ of amplified DNA following the manufacturer's protocol. PCR products were digested with CfoI, DraI, EcoRI, HaeIII, 
TABLE I. Trichomycetes used in this study

\begin{tabular}{|c|c|c|c|c|c|c|}
\hline Species & Isolate & Host & Locality & $\begin{array}{l}\text { ITS1 } \\
\text { (bp) }\end{array}$ & $\begin{array}{l}\text { ITS2 } \\
(\mathrm{bp})\end{array}$ & $\begin{array}{l}\text { GenBank 18S; } \\
\text { ITS1, ITS2. }\end{array}$ \\
\hline Capniomyces stellatus Peterson \& Lichtwardt & MIS-10-108 & Capniidae & Missouri, USA & - & - & AF007531 \\
\hline \multirow[t]{2}{*}{$\begin{array}{l}\text { Furculomyces boomerangus (Williams \& Lichtw.) } \\
\text { Williams \& Lichtw. }\end{array}$} & AUS-42-7 & Procladius ?paludicola & Victoria, Australia & 250 & 400 & $\begin{array}{l}\text { AF007535; AF277009; } \\
\text { AF } 277010\end{array}$ \\
\hline & AUS-77-4 & Tanytarsus nr. inextentus & Tasmania, Australia & 250 & 400 & AF277013 \\
\hline \multirow{2}{*}{$\begin{array}{l}\text { Genistelloides hibernus Peterson, Lichtw. \& } \\
\text { Horn }\end{array}$} & AL-7-10 & Allocapnia sp. & Alabama, USA & 350 & 400 & \\
\hline & TN-11-1 & Allocapnia sp. & Tennessee, USA & 1000 & 850 & AF007536 \\
\hline Simuliomyces spica Peterson \& Lichtw. & $\mathrm{TN}-1-11$ & Allocapnia sp. & Tennessee, USA & 350 & 400 & \\
\hline Smittium angustum Williams \& Lichtw. & AUS-126-30 & Tanytarsus sp.? & West Australia, Australia & 250 & 400 & AF277005; AF277006 \\
\hline Smittium annulatum Lichtwardt & CR-143-8 & Simuliidae & Costa Rica & 700 & 900 & AF277024 \\
\hline Smittium caudatum Lichtw. \& Grigg & KS-1-2 & Chironomidae & Kansas, USA & 500 & 1100 & $\begin{array}{l}\text { AF277031; AF277032; } \\
\quad \text { AF277033 }\end{array}$ \\
\hline \multirow[t]{2}{*}{ Smittium coloradense Lichtw. \& Williams } & RMBL-13-41 & Cricotopus sp.? & Colorado, USA & 700 & 1000 & AF277041; AF277042 \\
\hline & RMBL-13-49 & Orthocladius sp.? & Colorado, USA & 700 & 1000 & \\
\hline \multirow[t]{6}{*}{ Smittium commune Lichtw. \& Grigg } & DGK-2-3 & Chironomidae & Kansas, USA & 700 & 900 & \\
\hline & KS-12-13 L & Orthocladius sp. & Kansas, USA & 700 & 900 & \\
\hline & KS-2-21 & Chironomidae & Kansas, USA & 700 & 900 & AF277034 \\
\hline & KS-5-2 & Chironomidae & Kansas, USA & 700 & 900 & \\
\hline & KS-6-6 & Chironomidae & Kansas, USA & 700 & 900 & AF277035; AF277036 \\
\hline & OK-8-4 & Chironomidae & Oklahoma, USA & 700 & 900 & \\
\hline \multirow[t]{10}{*}{ Smittium culicis Manier } & ARG-X-3 & Culex renatoi & Argentina & 900 & 800 & \\
\hline & ARG-X-4 & Aedes albifasciatus & Argentina & 900 & 800 & \\
\hline & AUS-62-17 & Limonia sp. & Australia & 900 & 800 & \\
\hline & AUS-62-6 & Austrothaumalea sp. & Victoria, Australia & 900 & 800 & AF277012 \\
\hline & AUS-77-5 & Tanytarsus nr. inextentus & Tasmania, Australia & 900 & 800 & \\
\hline & CAL-X-1 & Aedes melanimom & California, USA & 900 & 800 & \\
\hline & CAN-X-1 & Prosimulium sp. & Canada & 900 & 800 & \\
\hline & FRA-6-16 & Chirnomidae & France & 900 & 800 & \\
\hline & WYO-51-11 & Aedes sticticus & Wyoming, USA & 900 & 800 & AF277047; AF277048 \\
\hline & ZEA-6-3 & Culex pervigilans & North Island, New Zealand & 900 & 800 & \\
\hline Smittium culicisoides Lichtwardt & CR-253-12 & Chironomidae & Costa Rica & $850-900$ & 800 & AF277028 \\
\hline
\end{tabular}




\begin{tabular}{|c|c|c|c|c|c|c|}
\hline Species & Isolate & Host & Locality & $\begin{array}{l}\text { ITS1 } \\
\text { (bp) }\end{array}$ & $\begin{array}{l}\text { ITS2 } \\
\text { (bp) }\end{array}$ & $\begin{array}{l}\text { GenBank 18S; } \\
\text { ITS1, ITS2. }\end{array}$ \\
\hline \multirow[t]{14}{*}{ Smittium culisetae Lichtwardt } & ARG-X-1 & Aedes crinifer & Argentina & 450 & 650 & \\
\hline & ARG-X-2 & Culex dolosus & Argentina & 450 & 650 & \\
\hline & ARG-X-5 & Aedes crinifer & Argentina & 450 & 650 & \\
\hline & AUS-2-10 & Chironomus alternans & New South Wales, Australia & 450 & 650 & \\
\hline & AUS-2-8 & Chironomus alternans & New South Wales, Australia & 450 & 650 & AF277007; AF277008 \\
\hline & CAL-X-2 & Culiseta incidens & California, USA & 450 & 650 & \\
\hline & COL-18-3 & Culiseta impatiens & Colorado, USA & 450 & 650 & $\begin{array}{l}\text { AF007540, D29950, } \\
\text { AF277029 }\end{array}$ \\
\hline & FL-X-1 & Aedes albopictus & Florida, USA & 450 & 650 & \\
\hline & FRA-7-1 & Dasyhelia sp. & France & 450 & 650 & \\
\hline & HAW-5-8 & Aedes albopictus & Hawaii, USA & 450 & 650 & \\
\hline & HAW-E-2 & Culicidae & Hawaii, USA & 450 & 650 & \\
\hline & JAP-30-3 & Culex sp. & Japan & 450 & 650 & \\
\hline & JAP-77-8 & Culicidae & Japan & 450 & 650 & \\
\hline & LEA-7-2 & Simulium vittatum & Kansas, USA & 450 & 650 & \\
\hline \multirow[t]{3}{*}{ Smittium cylindrosporum Lichtw. \& Arenas } & CHI-19-3 & Cricotopus sp. & Chile & 500 & 1100 & \\
\hline & CHI-20-4 & Cricotopus sp. & Chile & 500 & 1100 & AF277017 \\
\hline & CHI-27-1 & Cricotopus sp. & Chile & 500 & 1100 & AF277018 \\
\hline Smittium dipterorum Lichtwardt & CR-253-14 & Simulium sp. & Costa Rica & 800 & 1100 & AF277026; AF277027 \\
\hline Smittium dipterorum? & CR-141-17 & Simulium sp. & Costa Rica & 900 & 1000 & AF277023 \\
\hline \multirow{2}{*}{ Smittium fecundum Lichtw. \& Williams } & RMBL-61-13 & Psectrocladius sp. & Colorado, USA & 800 & 800 & \\
\hline & RMBL-64-5 & Psectrocladius sp. & Colorado, USA & 800 & 800 & AF277044 \\
\hline $\begin{array}{l}\text { Smittium gravimetallum Lichtw., Ferrington \& } \\
\text { Hayford, nom. prov. }\end{array}$ & KS-F1-3 & Dicrotendipes sp. & Kansas, USA & 800 & 800 & AF277037; AF277038 \\
\hline \multirow[t]{2}{*}{ Smittium imitatum Lichtw. \& Arenas } & CHI-20-11 & Simulium sp. & Chile & 800 & 800 & AF277016 \\
\hline & CHI-9-4 & Simulium sp. & Chile & 800 & 800 & AF277021 \\
\hline Smittium megazygosporum Manier \& Coste & SC-DP-2 & Simulium vittatum & South Carolina, USA & 800 & 800 & AF277045 \\
\hline Smittium morbosum Sweeney & AUS-X-1 & Anopheles hilli & New South Wales, Australia & 550 & 800 & AF277014 \\
\hline $\begin{array}{l}\text { Smittium mucronatum Manier \& Mathiez ex } \\
\text { Manier }\end{array}$ & FRA-12-3 & Psectrocladius sordidellus & France & 700 & 1100 & AF277030 \\
\hline \multirow[t]{2}{*}{ Smittium orthocladii Manier emend. Lichtw. } & OK-4-19 & Chironomidae & Oklahoma, USA & 700 & 800 & AF277040 \\
\hline & TN-3-12 & Chironomidae & Tennessee, USA. & 700 & 900 & \\
\hline Smittium perforatum? Williams \& Lichtw. & RMBL-44-3 & Diamesa sp. & Colorado, USA & 700 & 800 & \\
\hline Smittium phytotelmatum Lichtw. & CR-219-1 & Chironomus sp. & Costa Rica & 700 & 1100 & AF277025 \\
\hline Smittium phytotelmatum? & CR-133-2 & Chironomus sp. & Costa Rica & 700 & 900 & AF277022 \\
\hline \multirow[t]{3}{*}{ Smittium simulatum Lichtw. \& Arenas } & CHI-8-3 & Aphrophila bidentata & Chile & 900 & 800 & \\
\hline & CHI-8-4 & Aphrophila bidentata & Chile & 800 & 800 & AF277019; AF277020 \\
\hline & CHI-8-7 & Aphrophila bidentata & Chile & 900 & 800 & \\
\hline
\end{tabular}




\begin{tabular}{|c|c|c|c|c|c|c|}
\hline Species & Isolate & Host & Locality & $\begin{array}{r}\text { ITS1 } \\
\text { (bp) }\end{array}$ & $\begin{array}{r}\text { ITS2 } \\
(\mathrm{bp})\end{array}$ & $\begin{array}{l}\text { GenBank 18S; } \\
\text { ITS1, ITS2. }\end{array}$ \\
\hline \multirow{4}{*}{ Smittium simulii Lichtwardt } & CAL-8-1 & Simulium argus & California, USA & 700 & 900 & AF277015 \\
\hline & JAP-31-7 & Simulium uchidai & Japan & 700 & 900 & \\
\hline & JAP-51-5 & Simulium sp. & Japan & 700 & 900 & \\
\hline & SWE-8-4 & Diamesa sp. & Sweden & 700 & 900 & AF277046 \\
\hline \multirow[t]{2}{*}{ Smittium tipulidarum Williams \& Lichtw. } & RMBL-31-1 & Tipulidae & Colorado, USA & 800 & 900 & AF277043 \\
\hline & RMBL-31-2 & Tipulidae & Colorado, USA & 800 & 900 & \\
\hline \multirow{2}{*}{$\begin{array}{l}\text { Smittium tronadorium Lichtw., Ferrington \& } \\
\text { López Lastra }\end{array}$} & ARG-24-2F & Diamesinae & Argentina & 800 & 800 & AF277004 \\
\hline & ARG-24-20F & Diamesinae & Argentina & 800 & 800 & \\
\hline \multirow[t]{12}{*}{ Smittium sp. } & AR-19-4L & Chironomidae & Arkansas, USA & 700 & 800 & \\
\hline & AUS-59-L & Cardiocladius australiensis & Victoria, Australia & 700 & 900 & AF277011 \\
\hline & AUS-59-5S & C. australiensis & Victoria, Australia & 350 & 400 & \\
\hline & CR-259-4 & Chironomidae & Costa Rica & 1000 & 1000 & \\
\hline & MO-3-15 & Chironomidae & Missouri, USA & 700 & 900 & \\
\hline & MO-3-16 & Chironomidae & Missouri, USA & 700 & 900 & \\
\hline & OK-3-22 & Chironomidae & Oklahoma, USA & 800 & 900 & AF277039 \\
\hline & RMBL-48-8 & Chironomidae & Colorado, USA & 750 & 800 & \\
\hline & SWE-3-5 & Chironomidae & Sweden & 700 & 900 & \\
\hline & SWI-4-13 & Chironomidae & Switzerland & 700 & 900 & \\
\hline & SWI-7-6 & Chironomidae & Switzerland & 700 & 900 & \\
\hline & TN-3-16 & Chironomidae & Tennessee, USA & 700 & 900 & \\
\hline Entomophaga aulicae (Reichardt) Humber & - & - & - & - & - & U35394 \\
\hline Entomophthora muscae (Cohn) Fresenius & - & - & - & - & - & D29948 \\
\hline Conidiobolus coronatus (Constantin) Batko & - & - & - & - & - & D29937 \\
\hline Zoophthora radicans (Brefeld) Batko & - & - & - & - & - & D29949 \\
\hline Dipsacomyces acuminosporus Benjamin & - & - & - & - & - & AF007534 \\
\hline Linderina pennispora Raper \& Fennell & - & - & - & - & - & AF007538 \\
\hline Kickxella alabastrina Coemans & - & - & - & - & - & AF007537 \\
\hline Coemansia reversa van Tiegh. \& Le Monn. & - & - & - & - & - & AF007533 \\
\hline Spirodactylon aureum Benjamin & - & - & - & - & - & AF007541 \\
\hline Spiromyces aspiralis Benny \& Benjamin & - & - & - & - & - & AF007543 \\
\hline Spiromyces minutus Benjamin & - & - & - & - & - & AF007542 \\
\hline Mucor racemosus Fresenius & - & - & - & - & - & X54863 \\
\hline Syncephalastrum racemosum Cohn & - & - & - & - & - & X89437 \\
\hline Endogone pisiformis Berk. & - & - & - & - & - & X58724 \\
\hline Glomus intraradices Schenck \& G. S. Smith & - & - & - & - & - & X 58725 \\
\hline Acaulospora spinosa Walker \& Trappe & - & - & - & - & - & $\mathrm{Z} 14004$ \\
\hline $\begin{array}{l}\text { Gigaspora gigantea (Nicol. \& Gerd.) Gerde- } \\
\text { mann \& Trappe }\end{array}$ & - & - & - & - & - & $\mathrm{Z} 14010$ \\
\hline Blastocladiella emersonii Cantino \& Hyatt & - & - & - & - & - & M54937 \\
\hline
\end{tabular}

Kickxella alabastrina Coemans

Spiromyces aspiralis Benny \& Benjamin

Spiromyces minutus Benjamin

Syncephalastrum racemosum Cohn

Endogone pisiformis Berk.

Gigaspora gigantea (Nicol. \& Gerd.) Gerde-

Blastocladiella emersonii Cantino \& Hyat 
HindIII, Hinfl, RsaI and Sau3AI (Promega Corp., Madison, Wisconsin). Incubation was held in a water bath at $37 \mathrm{C}$ for $3-4 \mathrm{~h}$. Restriction products were electrophoresed in $2 \%$ agarose gels in 1X TAE buffer. Size of restriction products was estimated by comparison with a molecular size marker (100 bp DNA Ladder, Promega Corp., Madison, Wisconsin), which was included in duplicate on all gels.

Cloning and sequencing.-PCR products were cut from the gel and purified using the QLAquick Gel Extraction kit (QIAGEN Inc., Valencia, California). Cleaned PCR products were cloned using either the Prime PCR Cloner Cloning System (5 Prime-3 Prime Inc., Boulder, Colorado) or the pGEM-T Easy Vector System (Promega Corp., Madison, Wisconsin) cloning kit. Putative positive colonies were screened for the insert by PCR amplification. Recombinant bacterial colonies were extracted with QIAprep Spin Miniprep kit (QIAGEN Inc., Valencia, California) and were sequenced in a LI-COR 4000L DNA Sequencer apparatus using the Thermo Sequenase fluorescent labeled primer cycle sequencing kit (Amersham Pharmacia Biotech Inc., Piscataway, New Jersey). Direct sequencing was performed in an ABI PRISM 310 DNA sequencing apparatus (Perkin-Elmer Corp., Foster City, California) at the Biochemical Research Service Laboratory, University of Kansas. Both strands of each rDNA fragment were sequenced. Overlapping sequencing reactions for the $18 \mathrm{~S}$ rDNA were done using primers Z411G, Z31G (O'Donnell et al 1998), NS41, NS51 (Simon et al 1992) and two primers for Harpellales, T1: 5'AACCAATGGGGGCAACCTCTTACTT-3' (position 223-244 in Saccharomyces cerevisiae $18 \mathrm{~S}$ rDNA) and T8: 5'-CATCGTGCTGGGGATAGTCCAT-3' (position 1630-1650 in $S$. cerevisiae $18 \mathrm{~S}$ rDNA). Gene regions for the $18 \mathrm{~S}, 5.8 \mathrm{~S}$ and $28 \mathrm{~S}$ rRNA genes were identified according to those of $S$. cerevisiae (GenBank M27607, J01353) and to those of some Harpellales already published (O' Donnell et al 1998). Sequences have been deposited in the GenBank Database and are identified by the accession numbers listed in TABLE I.

Data analyses.-Restriction digest banding patterns were coded. The absence of a target site and the length of amplified ITS1 and 2 were considered as additional phenotypes. The similarity matrix was obtained by using Simple Matching Coefficient as specified in the NTSYS-PC program (Rohlf 1993). Dendrograms were constructed by SAHN clustering method using UPGMA (unweighted pair-group method using arithmetic averages) cluster analysis to visualize relationships. The cophenetic correlation index was assessed by MXCOMP.

Alignment of sequences was done with CLUSTAL W (Thompson et al 1994); default settings for GOP and GEP were used ( 10 and 0.05 , respectively). Alignments were visually inspected and edited to maximize for homology. Two sequences from Kickxellales and from Entomophthorales (TABLE I) were used to root the cladograms. Fourteen additional sequences downloaded from GenBank for comparison with ingroup sequences are listed in TABLE I. Consensus sequences were obtained for those species with more than one sequence using SEQUENCE NAVIGATOR v. 1.01 (Perkin-Elmer Corp., Foster City, California). The IUPAC code was used for ambiguous residues. Maximum parsi- mony analysis was performed via the heuristic search option in PAUP* 4.0 (Swofford 1999) using stepwise addition (simple and random sequence addition of 10 and 100 replicates) and TBR branch swapping. Search settings were as follows: steepest descent option not in effect, MulTrees option in effect, zero length branches were set to collapse to yield polytomies, and multistate taxa were considered as uncertainty. Characters were treated as unordered. Gaps were treated as missing and all ambiguously aligned regions were excluded from the analyses. Support for internal branches was evaluated by bootstrap analyses from 500 heuristic searches and by decay indices (Bremer 1988) calculated using TREEROT (Sorenson 1996). Pairwise distance (uncorrected "p") between sequences was done with PAUP*. Constraint and unconstraint tree topologies were compared with the Kishino-Hasegawa test implemented in PAUP*. Alignments have been deposited in TreeBASE (S499, M726, M727).

RESULTS

ITS length variation and RFLP.-As deduced from comparison with a molecular marker, the ITS 1 region ranged from 250 to about $1000 \mathrm{bp}$, while the ITS2 region ranged from $400 \mathrm{bp}$ to about $1100 \mathrm{bp}$ (TABLE I, FIGS. 1, 2). The greatest length variation was determined to be in the amplified ITS 1, where at least 10 different lengths were recorded. Particularly within Smittium, the size of the complete ITS region, including the $5.8 \mathrm{~S}$ gene, ranged between 650 bp in Smittium angustum AUS-126-30 and 2000 bp in Smittium sp. CR-259-4 (TABLE I). Eight endonucleases, EcoRI, CfoI, DraI, HaeIII, HindIII, Hinfl, RsaI and Sau3A1, were used to generate RFLP. In general, there was good agreement between size estimates for the undigested PCR products and the sums of fragment sizes, but some anomalies were observed: the sum of fragment sizes obtained with Sau3A1 in CR259-4 and CR-253-14 were higher than the estimated size. Coded ITS-RFLP patterns rendered the dendrogram depicted in FIG. 3 with a high cophenetic correlation coefficient $(r=0.963)$.

Some taxa for which multiple isolates were scored provided the basis for intraspecific comparison of ITS-RFLP (FIG. 3). With the exception of two Argentinean samples ARG-X-1 and ARG-X-2, the remaining 12 Smittium culisetae isolates shared identical restriction patterns, despite their occurrence in different countries and continents (e.g., USA, France, Australia, or Japan). However, isolate JAP-77-8 showed an additional 400 bp band for ITS2. Three RsaI profiles were encountered in the ITS1 of Smittium culicis; isolates FRA-6-16 and ZEA-6-3 exhibited unique patterns. Particularly for isolate FRA-6-16, the sum of fragment sizes did not agree with the estimated size of undigested product. The ITS2 of S. culicis isolates 

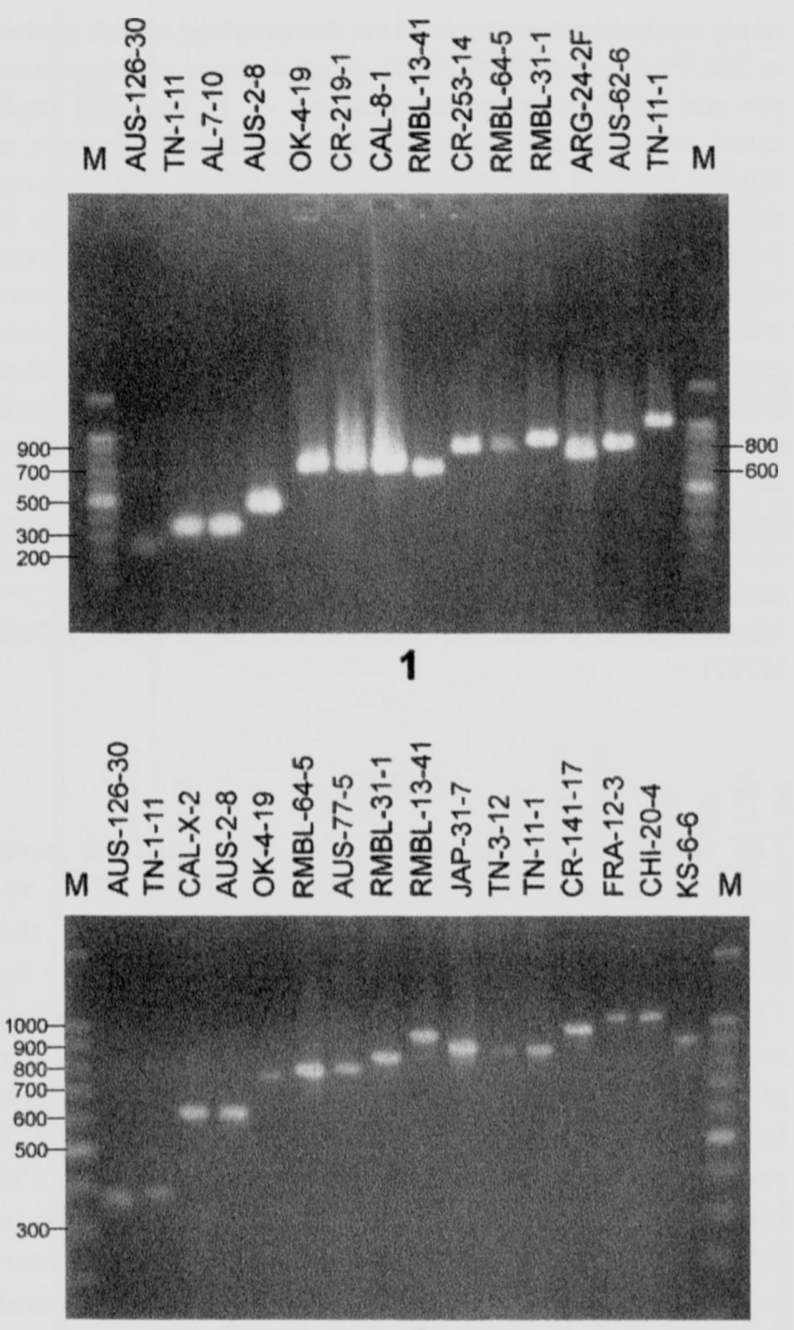

2

FIGS. 1, 2. Internal transcribed spacer (ITS) length polymorphism in some harpellean fungi. 1. ITS1 length variation. 2. ITS2 length variation. M stands for molecular marker. Band sizes (base pairs) of the marker are indicated. Isolate numbers are indicated for each lane. For complete reference, see TABLE I.

was also variable; for instance, isolates WYO-51-11, CAN-X-1 and ZEA-6-3 lacked Hinfl target sites. Excluding isolate FRA-6-16, remaining $S$. culicis isolates formed a cluster with $87 \%$ similarity (FIG. 3). In $S$. simulii, the ITS1 was more homogeneous than the ITS2, where sequence variation was detected with HaeIII and DraI, and resulted in isolates that did not group together (FIG. 3). Similarly, S. cylindrosporum isolates showed variability in ITS2 profiles obtained with DraI, Sau3AI and RsaI, while the ITS1 restriction profiles were identical. Though only two strains each of Smittium orthocladii, S. phytotelmatum and S. dipterorum were studied, high intraspecific variation was observed in one or both spacers. Consequently, they failed to cluster co-specifically in the dendrogram (Fig. 3). In contrast, $S$. coloradense and $S$. tipulidarum isolates formed separate groups within which no variation was detected. Some species shared identical ITS-RFLP or had a high level of similarity. For example, the two isolates of $S$. tronadorium and one isolate of $S$. imitatum CHI-9-4 exhibited identical patterns, while $S$. culicisoides and $S$. fecundum shared 91\% similarity. Likewise, S. gravimetallum KS-F1-3 and S. megazygosporum SC-DP-2 showed $89 \%$ similarity. The Australian Smittium isolate AUS-59-5S had 94\% similarity with two isolates belonging to two different genera, Simuliomyces spica and Genistelloides hibernus (FIG. 3). Significant variation in length and RFLP was observed between strains of $G$. hibernus included in this analysis, TN-11-1 and AL-7-10 (36\% similarity). On the other hand, Furculomyces boomerangus isolates AUS-42-7 and AUS-77-4 and Smittium angustum AUS126-30 had $100 \%$ similarity. Six unidentified Smittiums showed high similarity with members of the $S$. commune cluster.

ITS sequencing.-ITS1 and ITS2 sequences were obtained for isolates Smittium culisetae AUS-2-8, S. angustum AUS-126-30, S. simulatum CHI-8-4, S. culicis WYO-51-11, S. commune KS-6-6, S. coloradense RMBL13-41, S. gravimetallum KS-F1-3, S. caudatum KS-1-2 and $F$. boomerangus AUS-42-7. For isolates $S$. culisetae COL-18-3 and $S$. dipterorum CR-253-14, only the ITS1 was sequenced. In general, ITS1 and ITS2 sequences were unambiguously aligned in the regions corresponding to ribosomal genes (18S, 5.8S and 28S). For ITS1, the alignment included 11 sequences with different lengths ranging from $443 \mathrm{bp}$ (S. culisetae) to $807 \mathrm{bp}$ ( $S$. gravimetallum); the $\mathrm{G}+\mathrm{C}$ content varied from $18 \%$ in $S$. caudatum to $39.8 \%$ in $S$. dipterorum, suggesting that base composition may not be homogeneous among taxa. For the ITS2 data set, lengths varied from 557 bp in $S$. culisetae to 1042 bp in $S$. caudatum; the G+C content ranged from $23.5 \%$ in S. culisetae to $42.3 \%$ in $S$. simulatum. The alignment of seven ITS2 sequences included 1093 characters. Again, ribosomal gene sequences were unequivocally aligned. However, sequences of $S$. simulatum and $S$. culicis were completely alignable, having diverged by only $1.3 \%$. ITS1 and ITS2 sequences of Smittium angustum AUS-126-30 and Furculomyces boomerangus AUS- $42-7$ were identical, having a 240 bp ITS1 and a 370 bp ITS2.

Sequences were used to confirm restriction banding patterns. Also, we looked for introns that might account for the length variation by conducting a BLAST search in GenBank, but no intron sequences were found. 
PCR-RFLP from $18 S$ rDNA.-No evident length variation was observed in PCR-amplified products of the $18 \mathrm{~S}$ rRNA gene. Intraspecific variability in the $18 \mathrm{~S}$ rDNA was analyzed by RFLP of multiple isolates of Smittium culicis, S. culisetae, S. commune and S. simulii. Although no intraspecific variability was observed using EcoRI, CfoI, DraI, HaeIII, HindIII, Hinfl and RsaI, some species could not be differentiated (FIG. 4). Isolates of $S$. culisetae were clearly distinguished and formed a highly homogeneous cluster. Isolates of $S$. simulii, $S$. cylindrosporum, S. imitatum, $S$. orthocladii and $S$. commune were indistinguishable from each other. Another highly homogeneous group was formed by $S$. culicis, $S$. fecundum, $S$. simulatum and $S$. culicisoides. Other species like $S$. $t i$ pulidarum, $S$. annulatum, $S$. dipterorum, $S$. coloradense, S. mucronatum, S. caudatum, S. gravimetallum, and $S$. megazygosporum were also differentiated, suggesting that this molecule could be useful for phylogenetic studies directed at identifying species groups.

185 rDNA sequencing.-Thirty-two $18 \mathrm{~S}$ rDNA sequences were obtained for 24 morphological species of Smittium. Only 30-40 bp from both the $5^{\prime}$ and 3 ' ends were not sequenced. No intron sequences were found in the ingroup. The harpellean $18 \mathrm{~S}$ rDNA sequences have an average $\mathrm{G}+\mathrm{C}$ content of $43.6 \%$, ranging from $41 \%$ in Smittium morbosum to $45.9 \%$ in S. annulatum, suggesting that the base composition for this gene is rather homogeneous. Thirty-six ingroup sequences plus 4 outgroup sequences (Dipsacomyces acuminosporus and Linderina pennispora from Kickxellales, and Entomophaga aulicae and Entomophthora muscae from Entomophthorales) were aligned at 2055 positions. From these, 1305 phylogenetically uninformative characters and 365 ambiguously aligned positions were excluded from the analysis. As a result, 385 informative sites were used to infer tree topologies.

The same three equally parsimonious trees were obtained by simple and random stepwise addition (length $=886, \mathrm{CI}=0.638, \mathrm{RI}=0.771)$. The strict consensus gene tree depicted in Fig. 5 suggests that the $18 \mathrm{~S}$ rDNA sequences from Harpellales are derived from a unique common ancestor with a high confidence level (bootstrap $=100 \%$, decay $=28$ ) and that at least five lineages could be distinguished (numbered 1-5). Lineage 1 was composed solely of Smittium morbosum. Lineage 2 was formed by 8 taxa, although it was not strongly supported (bootstrap = $75 \%$, decay $=1$ ). Internal branches within this clade had better support. For instance, $S$. fecundum from the Rocky Mountains and S. culicisoides from Costa Rica formed a monophyletic clade with a $96 \%$ con- fidence level. Although statistical support for the branch connecting $S$. culicis and $S$. simulatum was low (bootstrap $=75 \%$, decay $=1$ ), both the $18 \mathrm{~S}$ data set and ITS-RFLP suggest that these two taxa are closely related. Smittium coloradense and S. mucronatum were also identified as putative sister taxa (FIGS. $3,5)$.

Lineage 3 was composed of two isolates of Smittium culisetae, AUS-2-8 and COL-18-3, and one isolate each of Capniomyces stellatus and Genistelloides hibernus. Monophyly of these isolates was well supported (bootstrap $=92 \%$, decay $=5$ ). The fourth lineage (4), had a $100 \%$ confidence level and comprised only Australian harpellids, two isolates of Furculomyces boomerangus and one of Smittium angustum. The same relationship was observed with ITS-RFLP. Lineage 5 included 19 isolates and had moderate statistical support (bootstrap $=86$, decay $=7$ ), though several nodes were unresolved. Isolates of $S$. simulii CAL-8-1 and SWE-8-4 failed to form a monophyletic group despite their $90 \%$ similarity in the ITS-RFLP analysis. Smittium imitatum isolates, CHI-20-11 and CHI-9-4, formed a monophyletic group with a very low bootstrap support $(53 \%$, decay $=1)$. The branch connecting S. cylindrosporum CHI-20-4 and CHI-27-1 was very well supported (bootstrap $=98 \%$, decay $=$ 8). On the other hand, a monophyletic origin of $S$. commune isolates KS-6-6 and KS-2-21 was supported by a bootstrap value of $91 \%($ decay $=2)$. Isolates of S. dipterorum [CR-253-14 and CR-141-17 (S. dipterorum?)] and S. phytotelmatum [CR-219-1 and CR-1332 (S. phytotelmatum?)] failed to form monophyletic clades. Nonetheless, $S$. dipterorum? formed a very well supported clade with $S$. gravimetallum and $S$. megazygosporum $(100 \%$ of bootstrap value, decay $=14)$. Smittium phytotelmatum? also appeared to be related to this clade but with a low confidence level (bootstrap $=59 \%$, decay $=3$ ).

Two topological constraints that forced monophyly of the genus Smittium were constructed. The first one forced the monophyly of the three Smittium lineages (i.e., 1, 2 and 5) plus $S$. angustum and $S$. culisetae. With this constraint, 225 equally parsimonious trees were found (length $=937, \mathrm{CI}=0.603, \mathrm{RI}=0.734$ ). This constraint was considered a significantly worse explanation of the data than the unconstrained tree, according to the Kishino-Hasegawa test (length difference $=51, \mathrm{SD}=9.406, t=5.422, P<0.0001)$. In the second topological constraint, monophyly of $S$. angustum with the remaining Smittiums was not enforced, resulting in 3 trees (length $=910$, CI $=$ $0.621, \mathrm{RI}=0.754)$. Though the second approach was more parsimonious than the first constraint, the tree length difference with respect to the unconstrained 
$\begin{array}{llll}0 & 30 & 50 & 80\end{array}$

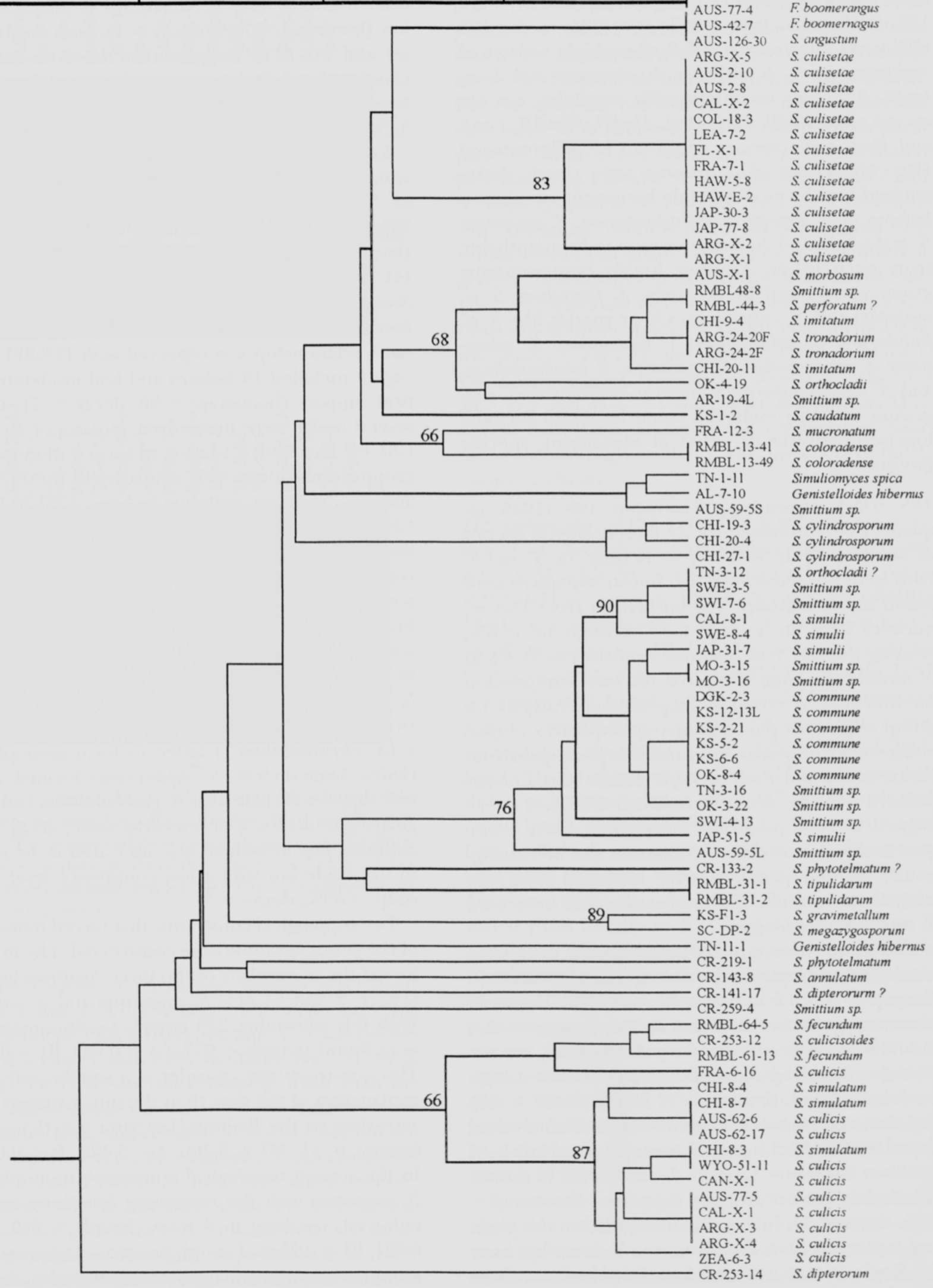


tree was statistically significant (length difference $=$ $24, \mathrm{SD}=7.253, t=3.308, P=0.001)$.

An additional, more inclusive analysis was conducted that included 13 sequences representing 6 orders of Zygomycota plus Blastocladiella emersonii (Chytridiomycetes) as outgroup. Ingroup sequences of Smittium imitatum, S. commune, S. culicis, S. culisetae and $S$. cylindrosporum were consensus between sequences used in the previous analysis. As a result, 36 sequences were aligned at 2081 positions of which 406 were phylogenetically informative. Twenty-four equally parsimonious trees were obtained and the strict consensus gene tree is depicted in Fig. 6 (length $=1374, \mathrm{CI}=0.476, \mathrm{RI}=0.693)$. Mucorales, Entomophthorales, Glomales and Harpellales formed strongly supported monophyletic clades (bootstrap $=99-100 \%$ ). Members of the Kickxellales did not form a monophyletic clade. However, the placement of Spiromyces as sister taxa was poorly supported (bootstrap $<50 \%$ ). The common origin of Harpellales and Kickxellales (excluding the Spiromyces clade) received a relatively low bootstrap interval $(68 \%)$.

\section{DISCUSSION}

In fungi, the entire ITS region is often between 600 and 800 bp (Gardes and Bruns 1993). The Harpellales studied had a longer ITS than expected. Nonetheless, such lengths have been reported in other fungi. Farmer and Sylvia (1998) observed in a variety of ectomycorrhizal fungi complete ITS regions ranging 850-1240 bp and Feibelman et al (1994) found that the ITS1 within isolates of Cantharellus ranged 250-1100 bp. In the zygomycete Entomophaga aulicae (Entomophthorales), the complete ITS region comprises 1100 bp (GenBank U35394). The RFLP analysis of PCR-amplified fragments is an appropriate technique for screening for variation in a large number of isolates. Usually, very small restriction products are unresolvable in $1 \%$ agarose and will contribute to underestimation of RFLP. Therefore we used $2 \%$ agarose gels for sizing fragments. As judged from comparison with patterns deduced from sequence data, $2 \%$ agarose gels worked sufficiently well. In addition to length variation, some cases of within-isolate heterogeniety were suggested by the data. Heterogeneity among the rDNA repeats, in size or presence of target sites, can result in extra bands leading to discrepancies between the actual size of the undigested PCR product and the sum of fragments. For instance, some copies of the ITS2 in isolates CR-2594 (Smittium sp.) and CR-253-14 (S. dipterorum) may have lost one or more sites for Sau3A1. Only in one case was an extra band detected that may be due to heterogeneity among rDNA repeats, but no attempts were made to sequence it. Our results suggest that ITS length and sequence variation make it unsuitable for phylogenetic studies among species of the genus Smittium as presently circumscribed.

In our effort to infer the evolutionary history of Trichomycetes, we included 18S rDNA in the analysis. Results from this data set were also surprising. Placement of Smittium culisetae within a clade composed of representatives of other genera (Capniomyces, Genistelloides and Furculomyces) together with the split distribution of Smittium species suggests that the genus may not be monophyletic. A possible explanation of the phylogenetic divergence could be the convergence of similar phenotypes that have evolved independently under similar environmental constraints. Many species of the genus Smittium are distinguished by very subtle features that may not represent synapomorphies. In other cases, morphological characters define robust groups.

Smittium morbosum, which formed a solitary lineage, has been reported to penetrate the gut cuticle (Sweeney 1981, Sato et al 1989), causing 50-90\% mortality in larvae of Anopheles hilli in Australia (Sweeney 1981). Sato et al (1989) in Japan and López Lastra (1990) in Argentina found that $S$. morbosum is able to infect many species of mosquitoes. Phylogenetic relationship with another invasive-but nonlethal-trichomycete, S. perforatum (Williams and Lichtwardt 1987), remains to be investigated. Isolate RMBL-44-3 was tentatively identified as $S$. perforatum, but after re-examination of morphological features, its taxonomic status is uncertain. However, RMBL-443 and a unidentified isolate RMBL-48-8 (Smittium sp.) appeared to be closely related. They showed some similarity with the Chilean species, S. imitatum, although there are no reports of $S$. imitatum from the USA. Lichtwardt and Arenas (1996) discussed the morphological similarity between $S$. simulatum and S. culicis, and they noted that they cannot be readily distinguished in culture using trichospore shape and size alone. Two taxonomically important characters, the holdfast and the branching pattern of the thalli,

$\leftarrow$

FIG. 3. UPGMA cluster analysis of 82 harpellean isolates using data from ITS-RFLP. Similarity was estimated with Simple Matching Coefficient. Isolates and their taxonomic status are indicated. Numbers above branches indicate shared percentage of similarity. Scale represents percentage of similarity. 

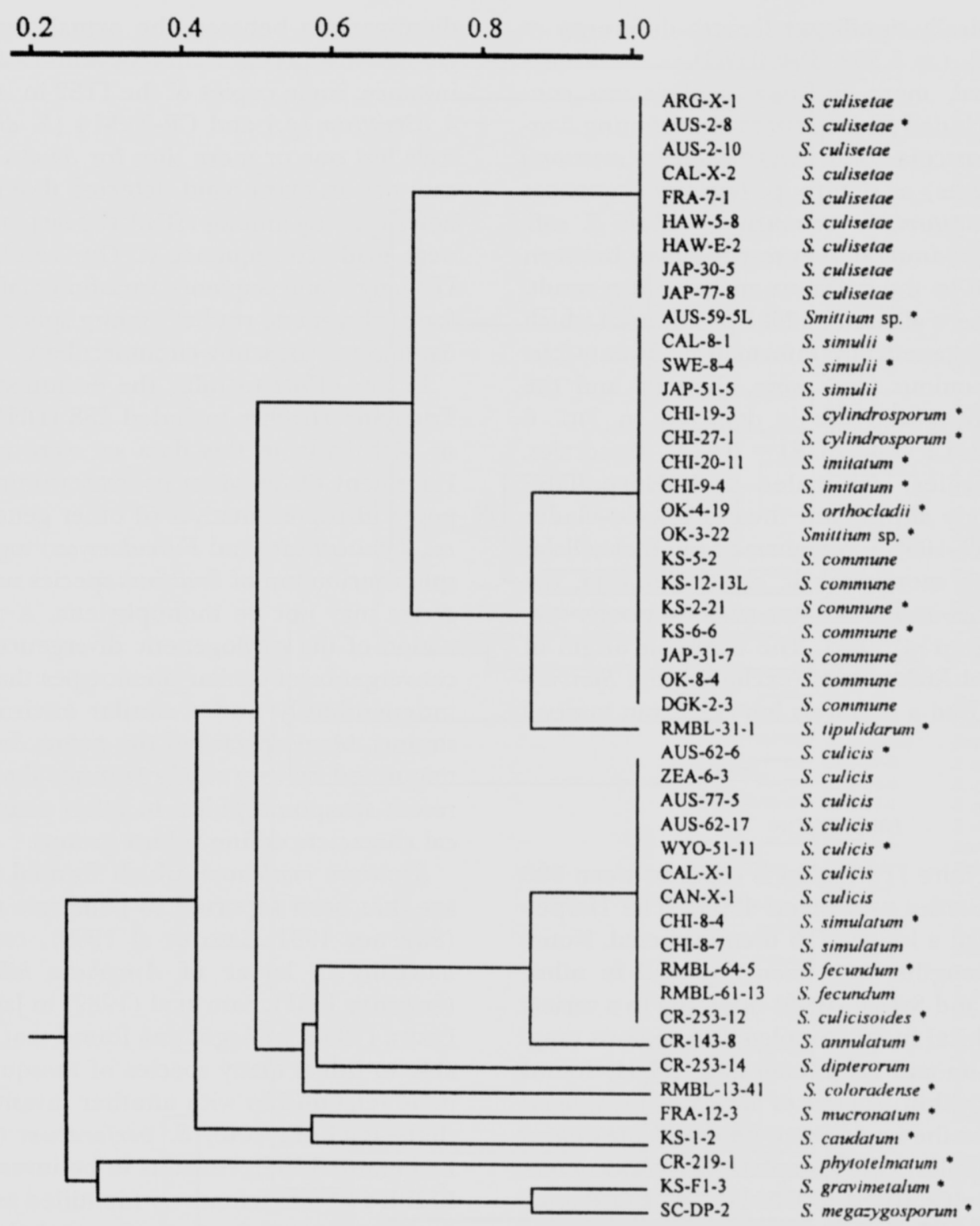

FIG. 4. Dendrogram derived from 18S-RFLP. Scale represents percentage of similarity. Isolate numbers and species names are indicated. Asterisks indicate isolates used for sequencing.

are used to distinguish them. Isozymically, these two taxa are very distinct (Grigg and Lichtwardt 1996), but our 18S rRNA gene phylogeny indicated that they are closely related. As indicated by its name, Smittium culicisoides is morphologically similar to $S$. culicis; trichospores of the two species vary slightly in average length to width ratio, and branching in thalli of $S$. culicis is more divergent than in $S$. culicisoides. The distinction of these two species was supported by isozyme patterns (Lichtwardt 1997). In the gene tree presented here, $S$. culicisoides appears as a sister taxon of $S$. fecundum. As a distinctive feature, S. fecundum produces a prolific series of short generative cells on fertile branches of mature thalli (Lichtwardt and Williams 1999). There is some conflict between results from the isozyme analysis, ITS-RFLP and the $18 \mathrm{~S}$ rDNA sequence analysis for $S$. annulatum CR143-8, S. coloradense RMBL-13-41 and S. caudatum KS$1-2$, such that their phylogenetic relationships are still unclear. The most recognizable feature of $S$. mucronatum is the very small nipple at the tip of the trichospore (Lichtwardt and Williams 1999). According to Moss and Young (1978), S. mucronatum and S. culicis may have lost the septum delimiting the generative cell. It would be very interesting to investigate if this constitutes a common feature among the members of that clade. Smittium culisetae is a very well characterized taxon for which highly homogeneous 


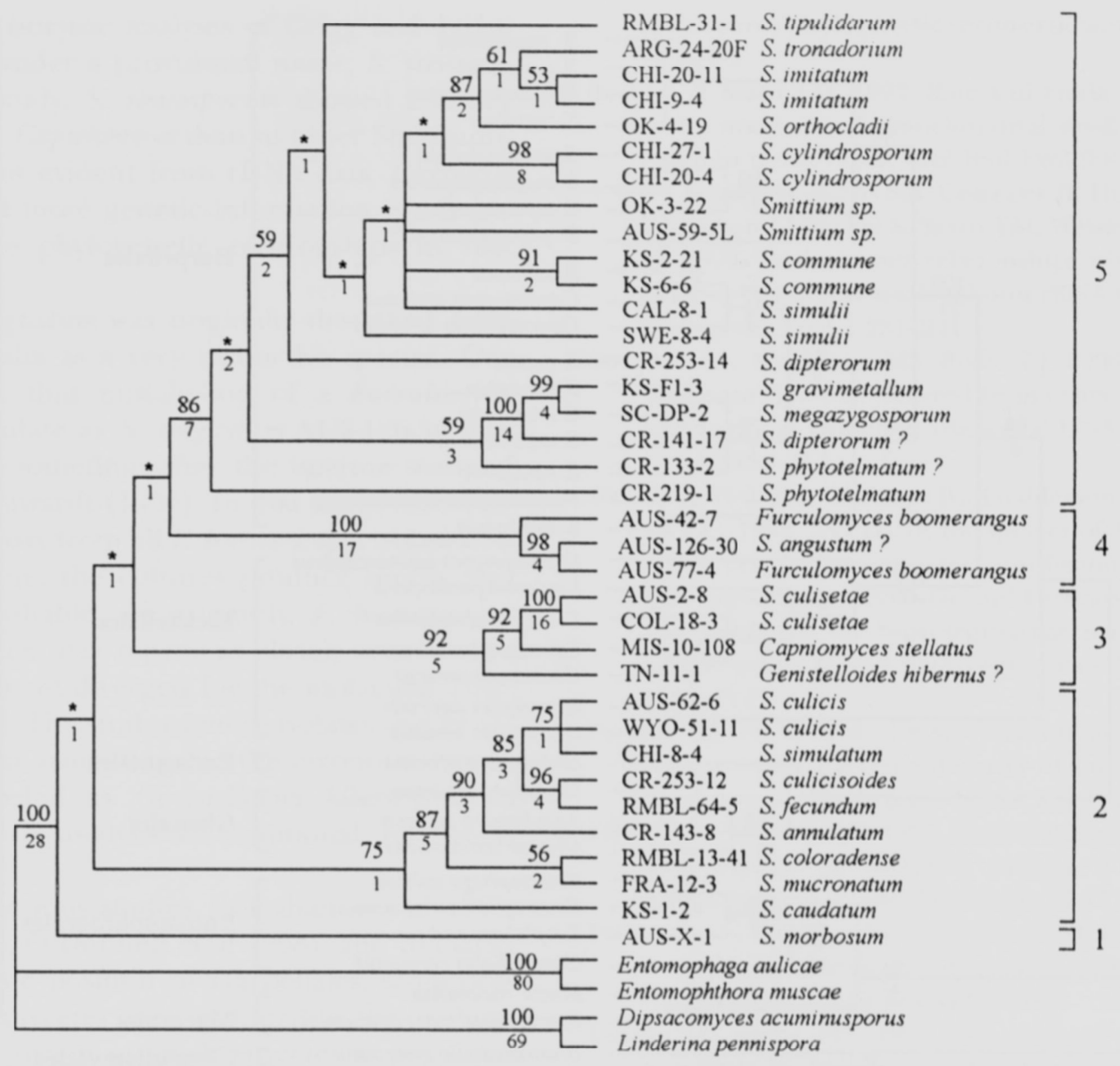

FIG. 5. Strict consensus of 3 equally parsimonious trees $(886$ steps, CI $=0.638, \mathrm{RI}=0.771)$ inferred from $18 \mathrm{~S}$ rDNA data set. Numbers above branches represent bootstrap values (above $50 \%$ from 500 replicates), while those below represent decay indices. Asterisks $(*)$ indicate branches that collapsed in the bootstrap tree. Five lineages (numbered 1-5) are indicated next to isolate numbers and species names.

isozymic patterns (Grigg and Lichtwardt 1996) and immunological data (Peterson and Lichtwardt 1987) were obtained. In the present study, 14 isolates from various geographic origins were studied. With the exception of isolates ARG-X-1 and ARG-X-2, the remaining isolates showed high homogeneity. Surprisingly, this taxon appears not to be monophyletic with other Smittium species studied based on the $18 \mathrm{~S}$ rDNA phylogeny. Horn (1989b) observed ultrastructural differences between $S$. culisetae and $S$. culicis associated with in vitro sporangiospore extrusion from trichospores. In $S$. culisetae, trichospores have pits in the sporangiospore wall and associated mucilage in the interwall layer only at the apical end. In contrast, $S$. culicis possesses pits and mucilage at both ends of its trichospores, and sporangiospores can be extruded from either end of the trichospore. Whether or not these traits are common within a lineage remains to be studied.

Smittium gravimetallum nom. prov. is attached to the hindgut cuticle of its host by a bulbous basal cell and produces trichospores with short collars (1-2 $\mu \mathrm{m})$. In contrast, the original description of $S . m e^{-}$ gazygosporum from France has no bulbous base, and trichospore collars are 3.5-4 $\mu \mathrm{m}$ long. Trichospores of both species overlap in size. Those of $S$. megazygosporum SC-DP-2 from South Carolina, USA, are variable in size, and thalli in culture do not produce basal cells nor is the structure of the basal cell in the host known. 18S rDNA gene data suggest that $S$. gravimetallum and $S$. megazygosporum may be conspecific, but more isolates should be collected and studied before considering them to be synonymous.

Morphological characters were re-examined when molecular data showed a high intraspecific variation. Both isolates of Smittium dipterorum were found in simuliid guts from Costa Rica (Lichtwardt 1997). Of the two, CR-253-14 should be considered as representative of the taxon, while the taxonomic status of the other (CR-141-17) is now uncertain. Smittium phyto- 


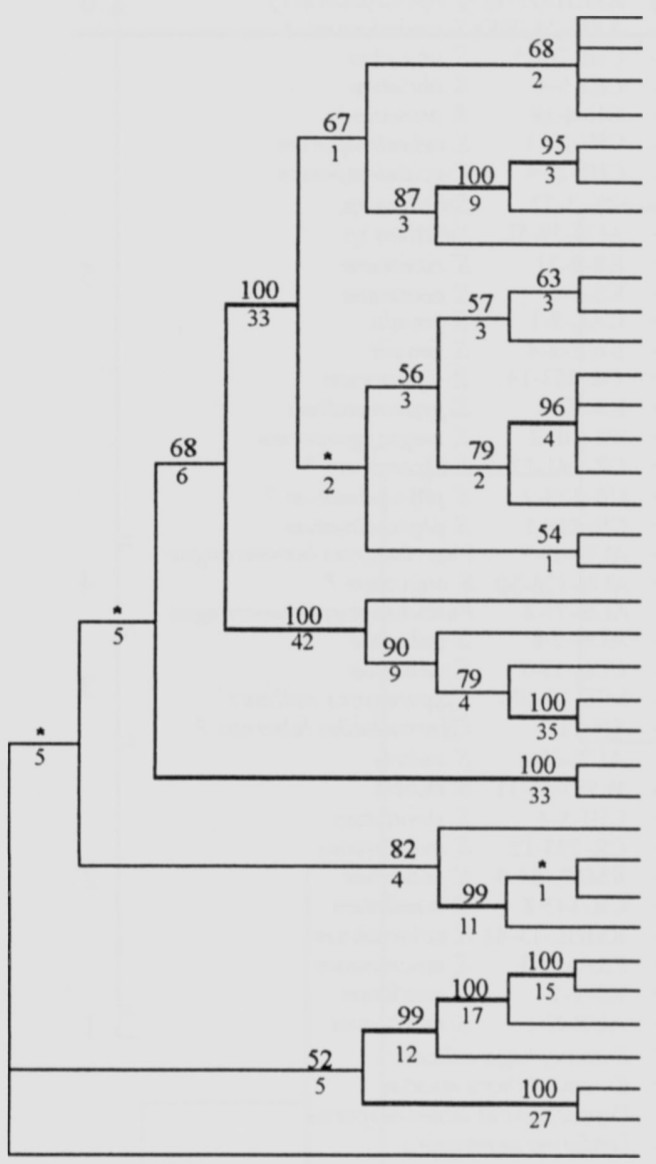

S. tipulidarum

S. commune

S. cylindrosporum

S. imitatum

S. gravimetallum

S. megazygosporum

S. dipterorum?

S. phytotelmatum?

S. culisetae

Capniomyces stellatus

Genistelloides hibermus

S. culicis

S. fecundum

S. annulatum

S. mucronatum

S. caudatum

Furculomyces boomerangus

S. morbosum

Dipsacomyces acuminosporus

Linderina pennispora

Kickxella alabastrina

Spirodactylon aureum

Coemansia reversa

Spiromyces aspiralis

Spiromyces minutus

Endogone pisiformis

Gigaspora gigantea

Acaulospora spinosa

Glomus intraradices

Entomophaga aulicae

Entomophthora muscae

Zoophthora radicans

Conidiobolus coronatus

Mucor racemosus

Syncephalastrum racemosum

Blastocladiella emersonii

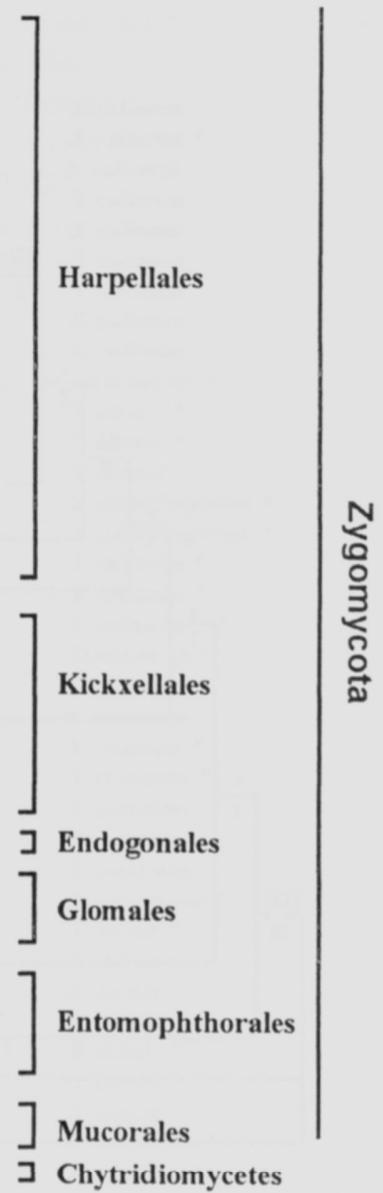

FIG. 6. Strict consensus of 24 equally parsimonious trees $(1374$ steps, CI $=0.476$, RI $=0.693)$ inferred from $18 \mathrm{~S}$ rDNA data set. Numbers above the branches represent bootstrap values (above $50 \%$ from 500 replicates), while those below represent decay indices. Asterisks (*) indicate branches that collapsed in the bootstrap tree.

telmatum isolates were obtained from bloodworms (Chironomus sp.) living in bromeliad leaf bases in Costa Rica (Lichtwardt 1994b). Even though CR-1332 was collected from the same bromeliad as the holotype, its branching pattern is somewhat different and the spores are longer and have a long collar. Morphological features of isolate CR-219-1 agree with the type description of $S$. phytotelmatum and is confirmed to be that species (Lichtwardt 1994b).

Trichospores of Smittium commune are distinct from other described species. Although $S$. morbosum has similar spore dimensions, they lack the characteristic median bulge. Also, S. tipulidarum has similar dimensions but the branching pattern of thalli is different. Isozymically, S. commune isolates formed two groupings interspersed with other taxa (Grigg and Lichtwardt 1996), but our molecular data indicate that this group is very homogeneous. Smittium cylindrosporum and $S$. imitatum were originally described from Chile (Lichtwardt and Arenas 1996). Based on molecular data, phylogenetic relationships were not very well supported. A similar situation was observed for $S$. imitatum and S. tronadorium, both from southern South America and very similar morphologically (Lichtwardt et al 1999). Further studies using other genes might indicate whether or not they are conspecific. Isolates of Smittium orthocladii showed variation for molecular characters. Of the two isolates, only OK-4-19 has dimorphic trichospores, which is the distinctive feature of the taxon. Our data indicate that cultures of Smittium simulii may not constitute a monophyletic lineage, though more isolates should be studied.

Australian isolates AUS-59-5S and AUS-59-5L were previously considered as S. elongatum (Lichtwardt and Williams 1990), but this identification was only tentative. The two isolates used were obtained from a mixed culture in which two morphotypes were distinguishable. Based on ITS-RFLP, AUS-59-5S showed more similarity to a Genistelloides than to other Smittiums, and AUS-59-5L was more related to $S$. commune and S. simulii. Likewise, isolate OK-3-22 was in- 
cluded in the isozyme analyses of Grigg and Lichtwardt (1996) under a provisional name, S. stenosporum. In that study, $S$. stenosporum showed a closer relationship to Capniomyces than to other Smittiums, but this was not evident from rDNA data. Certainly the addition of more genetic information is needed to fully resolve phylogenetic relationships in that clade.

Smittium angustum was originally described from Western Australia as a very distinctive species. Our results suggest that mislabeling of a Furculomyces boomerangus isolate as $S$. angustum AUS-126-30 may have occurred sometime after the isozyme study of Grigg and Lichtwardt (1996). In that study, AUS-12630 clustered apart from all $F$. boomerangus isolates. At the present time, the cultures produce spores that are indistinguishable. Alternatively, $F$. boomerangus and $S$. angustum may represent closely related taxa which have not yet diverged for the molecular characters surveyed. The study of more isolates and genes might clarify the issue. Because the taxonomic status of isolates labeled as Genistelloides hibernus is in doubt, sequence analysis of additional isolates is needed.

Based on previous studies (Nagahama et al 1995, Sugiyama 1998, O'Donnell et al 1998), and to clarify the phylogenetic position of Harpellales, sequences of several zygomycetes were included in the analysis. The kickxellid origin of Trichomycetes as proposed by Moss and Young (1978) was not strongly supported. As suggested by O' Donnell et al (1998), a polytomous radiation from a common ancestor appears to be the most parsimonious explanation.

\section{ACKNOWLEDGMENTS}

This research was supported by the National Science Foundation PEET grant (DEB-9521811) awarded to RWL and Leonard C. Ferrington, Jr. We thank Kerry O' Donnell who kindly provided all the primers used in this study, and Merlin M. White for the lyophylized cultures. They also kindly read the manuscript and offered a number of suggestions, as did Matías J. Cafaro.

\section{LITERATURE CITED}

Abouheif E, Zardoya R, Meyer A. 1998. Limitations of Metazoan $18 \mathrm{~S}$ rRNA sequence data: implications for reconstructing a phylogeny of the animal kingdom and inferring the reality of the Cambrian explosion. J Mol Evol 47:394-405.

Berbee ML, Yoshimura A, Sugiyama J, Taylor JW. 1995. Is Penicillium monophyletic? An evaluation of the phylogeny in the family Trichocomaceae from $18 \mathrm{~S}, 5.8 \mathrm{~S}$ and ITS ribosomal DNA sequence data. Mycologia 87:210-222.

Bremer K. 1988. The limits of amino acid sequence data in angiosperm phylogenetic reconstruction. Evolution 42: 795-803.

Bruns TD, Szaro TM. 1992. Rate and mode differences between nuclear and mitochondrial small subunit rRNA genes in mushrooms. Mol Biol Evol 9:836-855.

—_ Vilgalys R, Barns SM, Gonzalez D, Hibbett DS, Lane DJ, Simon L, Stickel S, Szaro TM, Weisburg WG, Sogin M. 1992. Evolutionary relationships within the fungi: analyses of nuclear small subunit rRNA sequences. Mol Phylogenet Evol 1:231-241.

Bunyard BA, Nicholson MS, Royse DJ. 1996. Phylogeny of the genus Agaricus inferred from restriction analysis of enzymatically amplified ribosomal DNA. Fungal Genet Biol 20:243-253.

Dick MW, Vick MC, Gibbings JG, Hedderson TA, Lopez Lastra CC. 1999. 18S rDNA for species of Leptolegnia and other Peronosporomycetes: justification for subclass taxa Saprolegniomycetidae and Peronosporomycetidae and division of the Saprolegniaceae sensu lato into the Leptolegniaceae and Saprolegniaceae. Mycol Res 103: $1119-1125$.

Farmer DJ, Sylvia DM. 1998. Variation in the ribosomal DNA internal transcribed spacer of a diverse collection of ectomycorrhizal fungi. Mycol Res 102:859-865.

Farr DF, Lichtwardt RW. 1967. Some cultural and ultrastructural aspects of Smittium culisetae (Trichomycetes) from mosquito larvae. Mycologia 59:172-182.

Feibelman T, Bayman P, Cibula WG. 1994. Length variation in the internal transcribed spacer of ribosomal DNA in chantarelles. Mycol Res 98:614-618.

Gardes M, Bruns TD. 1993. ITS primers with enhanced specificity for basidiomycetes-application to the identification of mycorrhizae and rusts. Mol Ecol 2:113118.

-, White TJ, Fortin JA, Taylor JW. 1991. Identification of indigenous and introduced symbiotic fungi in ectomycorrhizae by amplification of nuclear and mitochondrial ribosomal DNA. Can J Bot 69:180-190.

Gargas A, Taylor JW. 1995. Phylogeny of discomycetes and early radiations of the apothecial Ascomycotina inferred from SSU rDNA sequence data. Exp Mycol 19: $7-15$.

Grigg R, Lichtwardt RW. 1996. Isozyme patterns in cultured Trichomycetes. Mycologia 88:219-229.

Harrington FA, Pfister, DH, Potter D, Donoghue MJ. 1999. Phylogenetic studies within the Pezizales I. 18S rRNA sequence data and classification. Mycologia 91:41-50.

Hibbett DS, Pine EM, Langer E, Langer G, Donoghue MJ. 1997. Evolution of gilled mushrooms and puffballs inferred from ribosomal DNA sequences. Proc Natl Acad Sci USA 94:12002-12006.

-, Vilgalys R. 1991. Evolutionary relationships of Lentinus to the Polyporaceae: evidence from restriction analysis of enzymatically amplified ribosomal DNA. Mycologia 83:425-439.

Hillis DM, Dixon MT. 1991. Ribosomal DNA: molecular evolution and phylogenetic inference. Q Rev Biol 66:411453.

Horn BW. 1989a. Requirement for potassium and $\mathrm{pH}$ shift on host-mediated sporangiospore extrusion from tri- 
chospores of Smittium culisetae and other Smittium species. Mycol Res 93:303-313.

- 1989b. Ultrastructural changes in trichospores of Smittium culisetae and $S$. culicis during in vitro sporangiospore extrusion and holdfast formation. Mycologia 81:742-753.

— Lichtwardt RW. 1981. Studies on the nutritional relationship of larval Aedes aegypti (Diptera: Culicidae) with Smittium culisetae (Trichomycetes). Mycologia 73: 724-740.

Jeffries P, Young TWK. 1979. Ultrastructure of septa in Dimargaris cristalligena R. K. Benjamin. J Gen Microbiol 111:303-311.

Lichtwardt RW. 1986. The Trichomycetes, fungal associates of arthropods. New York: Springer-Verlag. 343 p.

- 1994a. Biogeography and fungal systematics. Can J Bot 73:S731-S737.

- 1994b. Trichomycete fungi living in the guts of Costa Rican phytotelm larvae and other lentic dipterans. Rev Biol Trop 42:31-48.

- 1996. Trichomycetes and the arthropod gut. In: Howard D, Miller D, eds. The Mycota VI. Human and animal relationships. Berlin: Springer-Verlag. p. 315330 .

- 1997. Costa Rica gut fungi (Trichomycetes) infecting lotic insect larvae. Rev Biol Trop 45:349-1383.

—, Arenas JM. 1996. Trichomycetes in aquatic insects from southern Chile. Mycologia 88:844-857.

- Ferrington LC, López Lastra CC. 1999. Trichomycetes in Argentinean aquatic insect larvae. Mycologia 91:1060-1082.

-, Williams MC. 1990. Trichomycete gut fungi in Australian aquatic insect larvae. Can J Bot 68:1057-1074.

- -1999 . Three Harpellales that live in one species of aquatic Chironomid larva. Mycologia 91: 396-399.

Lloyd-MacGilp SA, Chambers SM, Dodd JC, Fitter AH, Walker C, Young JPW. 1996. Diversity of the ribosomal internal transcribed spacers within and among isolates of Glomus mosseae and related mycorrhizal fungi. New Phytol 133:103-111.

Lobuglio K, Pitt JI, Taylor JW. 1993. Phylogenetic analysis of two ribosomal DNA regions indicates multiple independent losses of a sexual Talaromyces state among asexual Penicillium species in subgenus Biverticillium. Mycologia 85:592-604.

López Lastra CC. 1990. Primera cita de Smittium morbosum var. rioplatensis var. nov. (Trichomycetes: Harpellales) patógeno de 5 especies de mosquitos (Diptera: Culicidae) en la República Argentina. Rev Argent Micol 13: 14-18.

Manier J-F. 1973. Quelques aspects ultrastructuraux du Trichomycete Asellariale, Asellaria ligiae Tuzet ex Manier, 1950 ex Manier, 1968. C R Acad Sci Paris Ser D 276: 3429-3431.

Misra JK. 1998. Trichomycetes-fungi associated with arthropods: review and world literature. Symbiosis 24: 179-220.

- Lichtwardt RW. 2000. Illustrated genera of Trichomycetes: fungal symbionts of insects and other arthro- pods. Enfield, New Hampshire: Science Publishers, Inc. $166 \mathrm{p}$.

Moss ST. 1975. Septal structure in the Trichomycetes with special reference to Astreptonema gammari (Eccrinales). Trans Br Mycol Soc 65:115-127.

- 1979. Commensalism of the Trichomycetes. In: Batra LR, ed. Insect-fungus symbiosis: nutrition, mutualism, and commensalism. Montclair, New Jersey: Allanheld, Osmun and Co. p 175-227.

- Young TWK. 1978. Phyletic considerations of the Harpellales and Asellariales (Trichomycetes, Zygomycotina) and the Kickxellales (Zygomycetes, Zygomycotina). Mycologia 70:944-963.

Nagahama T, Sato H, Shimazu M, Sugiyama J. 1995. Phylogenetic divergence of the entomophthoralean fungi: evidence from nuclear $18 \mathrm{~S}$ ribosomal RNA gene sequences. Mycologia 87:203-209.

O’Donnell K, Cigelnik E, Benny GL. 1998. Phylogenetic relationships among the Harpellales and Kickxellales. Mycologia 99:624-639.

Peterson SW, Lichtwardt RW. 1987. Antigenic variation within and between populations of three genera of Harpellales (Trichomycetes). Trans Br Mycol Soc 88: 189-197.

Porter D, Smiley R. 1979. Ribosomal RNA molecular weights of Trichomycetes and Zygomycetes. Exp Mycol 3:188-193.

Rohlf FJ. 1993. NTSYS-PC, numerical taxonomy and multivariate analysis system. Version 1.80. Setauket, New York: Exeter Software. 244 p.

Saikawa M. 1977. Ultrastructure of septa of two species of Dimargaritaceae (Mucorales). J Japan Bot 52:200-203. - 1989. Ultrastructure of the septum in Ballocephala verrucospora (Entomophthorales, Zygomycetes). Can J Bot 67:2484-2488.

— two trichomycetous fungi attached to the hindgut lining of pill bugs. Can J Bot 75:1479-1484.

Sangar VK, Lichtwardt RW, Kirsh JAW, Lester RN. 1972. Immunological studies on the fungal genus Smittium (Trichomycetes). Mycologia 64:342-358.

Sato H, Shimada N, Aoki J. 1989. Light and electron microscopy of Smittium morbosum (Trichomycetes), newly recorded from Japan. Trans Mycol Soc Japan 30:51-59.

Simon L, Lalonde M, Bruns TD. 1992. Specific amplification of $18 \mathrm{~S}$ fungal ribosomal genes from vesicular-arbuscular endomycorrhizal fungi colonizing roots. Appl Environ Microbiol 58:291-295.

Slaymaker AK, Ferrington LC, Lichtwardt RW. 1998. Chironomidae-Trichomycete associations: a literature review. J Kansas Entomol Soc 71:490-500.

Sorenson HD. 1996. TreeRot. Computer program and documentation. Ann Arbor, Michigan:University of Michigan.

Starr AM, Lichtwardt RW, McChesney JD, Baer TA. 1979. Sterols synthesized by cultured Trichomycetes. Arch Microbiol 120:185-189.

Sugiyama J. 1998. Relatedness, phylogeny and evolution of the fungi. Mycoscience 39:478-511.

Sweeney AW. 1981. An undescribed species of Smittium 
(Trichomycetes) pathogenic to mosquito larvae in Australia. Trans Br Mycol Soc 77:55-60.

Swofford DL. 1999. PAUP* Phylogenetic analysis using parsimony (* and other methods). Version 4.0. Sunderland, Massachusetts: Sinauer Associates.

Thompson JD, Higgins DG, Gibson TJ. 1994. Clustal W: improving the sensitivity of progressive multiple sequence alignment through sequence weighting, position-specific gap penalties and weight matrix choice. Nucl Acid Res 22:4673-4680.

Vilgalys R, Hester M. 1990. Rapid genetic identification and mapping of enzymatically amplified ribosomal DNA from several Cryptococcus species. J Bacteriol 172:42384246.

Walker WF. 1984. 5S ribosomal RNA sequences from Zygomycotina and evolutionary implications. Syst Appl Microbiol 5:448-456.
White TJ, Bruns T, Lee S, Taylor J. 1990. Amplification and direct sequencing of fungal ribosomal RNA genes for phylogenetics. In: Innis MA, Gelfand DH, Snisky IJ, White TJ, eds. PCR protocols: a guide to methods and applications. New York: Academic Press. p 315-322.

Williams MC. 1983a. Spore longevity of Smittium culisetae (Harpellales, Legeriomycetaceae). Mycologia 75:171174.

. 1983b. Zygospores in Smittium culisetae (Trichomycetes) and observations on trichospore germination. Mycologia 75:251-256.

-, Lichtwardt RW. 1987. Three new species of Smittium (Trichomycetes) with notes on range extensions. Mycologia 79:832-838.

Young TWK. 1969. Ultrastructure of aerial hyphae in Linderina pennispora. Ann Bot 33:211-216. 